\title{
Reverse Evaluation of Failure Mode and Effects Analysis Model: A New Reliable Performance Measurement
}

\author{
Khaled M Alsubiaee ${ }^{1^{*}}$, Abdulmohsan F Alotaibi ${ }^{2}$, Abdulaziz S Alshehri $^{3}$, and Mohammed A Alassaf ${ }^{4}$ \\ ${ }^{1}$ Al Jouf University, Saudi Arabia \\ ${ }^{2}$ Ministry of Health, Saudi Arabia \\ ${ }^{3}$ Al Maarefa Colleges, Saudi Arabia \\ ${ }^{4}$ Food And Drug Administration (sFDA), Saudi Arabia \\ *Corresponding author: Khaled M Alsubiaee, Researcher, P.O. Box 2014 -Al Jouf University, Saudi Arabia, Tel: +966 558606615; E-mail: \\ Khaledmhd1@hotmail.com
}

Received date: August 01, 2017; Accepted date: August 29, 2017; Published date: August 31, 2017

Copyright: (c) 2017 Alsubiaee KM, et al. This is an open-access article distributed under the terms of the Creative Commons Attribution License, which permits unrestricted use, distribution, and reproduction in any medium, provided the original author and source are credited.

\begin{abstract}
After the World War II (WWII), the industrial era began. Therefore the risk management philosophy concerns shifted from error resolving to error prevention by predicting the causes. One of the most common processes used to decrease the failures is utilizing the Failure Mode and Effects Analysis (FMEA). FMEA approximates the probability based on Risk Priority Number (RPN). RPN is known for limitations in the process of RPN scoring system measuring the severity $(\mathrm{S})$, occurrence $(\mathrm{O})$, and detection of the failure (D). RPN is not an accurate, in determining the relative importance of failure. R-FMEA provides a proactive more reliable method using Kruskal-Wallis test. This article discusses with examples how a new suggested statistical model (R-FMEA) is enhancing the reliability of FMEA to predict errors.
\end{abstract}

Keywords: R-FMEA; FMEA; Reliability; Quality

\section{Introduction}

After the World War II (WWII), the industrial era began. Therefore the risk management philosophy concerns shifted from errors resolving to error prevention by predicting the causes. One of the most common processes used to decrease the failures is utilizing the Failure Mode and Effects Analysis (FMEA). FMEA is an official process used in healthcare to assess the safety of patients [1]. FMEA technique uses an inferential statistics and mathematics to determine the possible failures [2]. FMEA approximates the probability based on Risk Priority Number (RPN). RPN is known for limitations in the process of RPN scoring system measuring the severity $(\mathrm{S})$, occurrence $(\mathrm{O})$, and detection of the failure (D). The RPN is not an accurate, in determining the relative importance of failure [3].

Risk is a cognitive process is where the perception of an individual is considered a rate limiting step to interpret perceived the probability to real chance of loss or harm [4]. The concept of risk is usually linked to harmful behaviors [5]. The safety is a crucial element in providing healthcare services therefore, in the healthcare industry an efficient system is mandatory to protract the improvement and preserve control over the protection of healthcare services [6,7]. Approximately $40 \%$ of adverse events in Netherland is considered as preventable [8]. An evidence of risk reduction is related to identifying risk factors using proactive tools such as FMEA [9].

The healthcare service provision is a series multifaceted action with multidisciplinary interactions demand an appropriate tool (FMEA) utilized to improve the safety of the system within the hospital [10]. FMEA is a subjective dependant instrument uses an expert judgment of the risk factors derived from their backgrounds. The recognized failure is documented and prioritized; and the RPN is applied to predict the risks [11]. A United States department of Veterans Affairs National Center for Patient Safety developed a new version of FMEA called Healthcare FMEA (HFMEA) to utilize more complex matrix to increase reliability [10]. In 2008, the U.S. the costs of medical errors are approximately $\$ 17.1$ billion, which is equal to $0.72 \%$ of the healthcare annual budget [12].

\section{FMEA Reliability}

Using an unreliable instrument to evaluate the probability of accidents causes the inappropriate quality of service provided. The weakness of the FMEA related to the subjective verdict of the risks that lead to improper priorities setting based on RPN significance [11].

A control experiment study investigated the reliability of FMEA, shows that a significant difference in severity verdict in each group, to conclude that the FMEA is not a reliable tool [13]. Another drawback is the outcome inconsistency in the outcome of the FMEA [14]. FMEA is incapable to predict the tangible errors occurred, for that reason, merging FMEA with experience, learning, and trial and error most likely to moderately reduce the statistical type I and II errors [15].

\section{Reverse Evaluation of Failure Mode and Effects Analysis (R-FMEA) a performance reliable Model}

Reverse evaluation of FMEA (RFMEA) is an optional model suggested to demonstrate a reliable side of FMEA using comparison and combination of the recognized and unrecognized interpretations of the S, O, D, and RPN. The structure of the process stands for the input in the model which includes the multidisciplinary committee member's backgrounds, and experience [16]. The FMEA output reveals the RPN, known for uncertain reliability $[3,17]$. The $\mathrm{O}, \mathrm{S}$, and D are assigned to meet by concord of all members' cognitive perception 
Page 2 of 4

based on perceived risk. Furthermore, the members are allowed to reevaluating the steps in all meetings with comparison of error reported by the organization.

The committee members intuitively consign a numerical value to each step. The selected numbers vary, but the capacity of improvements merely on the RPN. By comparing and combining the statistical values of $\mathrm{O}, \mathrm{S}$, and $\mathrm{D}$ yearly; the reliability might be improved. As a consequence, the compatibility of R-FMEA and RPN enhance the reliability rather than merely RPN scores as shown in Figure 1

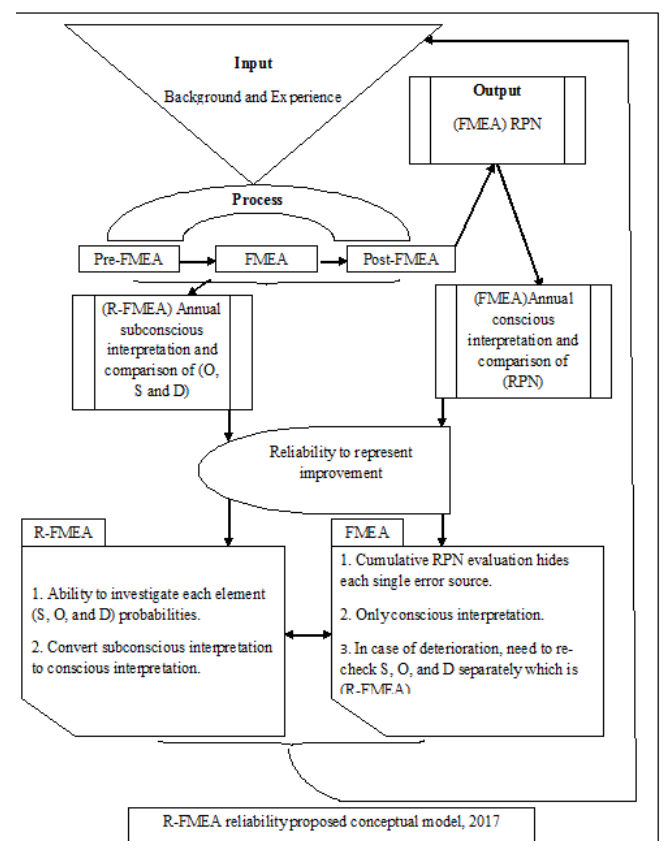

Figure 1: R-FMEA reliability proposed conceptual model.

\section{R-FMEA Statistics for Reliable Model}

The R-FMEA model predicts errors and compares $\mathrm{O}, \mathrm{S}$, and D for at least three years with minimum of five observations (evaluations) for each year to produce a reliable failure risk prediction and follow chisquare distribution. The years used in comparison are considered as samples for each item $(\mathrm{O}, \mathrm{S}$, and $\mathrm{D})$. Based on the nature of data used in evaluation, Kruskal-Wallis test seems to be the appropriate measurement test to predict the median differences [18]. Moreover, the requirements of Kruskal-Wallis test are met as each observation (evaluation) is considered as an independent variable; and no particular population distribution is required. Using the KruskalWallis test equation for each item as follow:

For Detection, the R-FMEA is

$\mathrm{R}_{\mathrm{FMEA}}-\mathrm{D}=\frac{12}{\mathrm{~N}(\mathrm{~N}+1)}\left(\frac{\mathrm{T} 1^{2}}{\mathrm{n} 1}+\frac{\mathrm{T}^{2}}{\mathrm{n} 2}+\ldots+\frac{\mathrm{Tk}^{2}}{\mathrm{nk}}\right)-3(\mathrm{~N}+1)$ Formula $(1)$

For Occurrence, the R-FMEA is

$\mathrm{R}_{\mathrm{FMEA}-0}=\frac{12}{\mathrm{~N}(\mathrm{~N}+1)}\left(\frac{\mathrm{T}^{2}}{\mathrm{n} 1}+\frac{\mathrm{T}^{2}}{\mathrm{n} 2}+\ldots+\frac{\mathrm{Tk}^{2}}{\mathrm{nk}}\right)-3(\mathrm{~N}+1) \quad$ Formula $(2)$
For Severity, the R-FMEA is

$\mathrm{R}_{\mathrm{FMEA}-\mathrm{S}}=\frac{12}{\mathrm{~N}(\mathrm{~N}+1)}\left(\frac{\mathrm{T} 1^{2}}{\mathrm{n} 1}+\frac{\mathrm{T} 2^{2}}{\mathrm{n} 2}+\ldots+\frac{\mathrm{Tk}^{2}}{\mathrm{nk}}\right)-3(\mathrm{~N}+1) \quad$ Formula (3)

Where is:

$\mathrm{N}$ : The total number of observations (evaluations) in all years for each item.

$\mathrm{T}$ : the sum of ranking in each year i.e. T1 for the first year, and T2 for second.

$\mathrm{k}$ : number of years.

$\mathrm{n}$ : number of evaluations each year.

df: degree of freedom which used in Chi-square distribution, $\mathrm{df}=$ $\mathrm{K}-1$.

The values of $\mathrm{R}_{\mathrm{FMEA}-\mathrm{O}}, \mathrm{R}_{\mathrm{FMEA}-\mathrm{S}}$, And $\mathrm{R}_{\mathrm{FMEA}-\mathrm{D}}$, compared separately with corresponding degree of freedom and significance level in Chisquare distribution table. Given the range of corresponding value, the $\mathrm{R}_{\mathrm{FMEA} \text { 's }}$ value accepted or rejected as long as it falls in the same range or out of the range respectively. The table with observations ranked by the lowest value provides precisely the level of improvements in failure occurrence, severity, and detection throughout compared years (Tables $1-4)$.

\section{Example:}

Detection, Occurrence, and Severity tables for Emergency quality department in a tertiary hospital for three consecutive years:

\begin{tabular}{|c|c|c|c|}
\hline Detection (D) & $\mathbf{2 0 1 5}$ & $\mathbf{2 0 1 6}$ & $\mathbf{2 0 1 7}$ \\
\hline Evaluation1 & 10 & 8 & 3 \\
\hline Evaluation2 & 9 & 7 & 3 \\
\hline Evaluation3 & 5 & 5 & 2 \\
\hline Evaluation4 & 6 & 4 & 2 \\
\hline Evaluation5 & 7 & 8 & 1 \\
\hline
\end{tabular}

Table 1: Detection observations by quality department in three years.

The first step is to rank all evaluations in compared years as follow:

\begin{tabular}{|c|c|c|c|}
\hline Detection (D) & $\mathbf{2 0 1 5}$ & $\mathbf{2 0 1 6}$ & $\mathbf{2 0 1 7}$ \\
\hline Evaluation1 & $10(15)$ & $8(12.5)$ & $3(4.5)$ \\
\hline Evaluation2 & $9(14)$ & $7(10.5)$ & $3(4.5)$ \\
\hline Evaluation3 & $5(7.5)$ & $5(7.5)$ & $2(2.5)$ \\
\hline Evaluation4 & $6(9)$ & $4(6)$ & $2(2.5)$ \\
\hline Evaluation5 & $7(10.5)$ & $8(12.5)$ & $1(1)$ \\
\hline Sum of ranks & 56 & 49 & 15 \\
\hline Mean of the ranks & 11.2 & 9.8 & 3 \\
\hline $\begin{array}{c}\text { Mean of evaluations (used } \\
\text { for conventional FMEA) }\end{array}$ & 7.4 & 6.4 & 2.2 \\
\hline
\end{tabular}

Table 2: Ranked detection observations table. 
Page 3 of 4

In case of more than one evaluation having the same rank, the mean of their rank should be given as it showed in brackets.

Using Formula (1)

For Detection, the R-FMEA is

$\mathrm{R}_{\text {FMEA-D }}=\frac{12}{\mathrm{~N}(\mathrm{~N}+1)}\left(\frac{\mathrm{T}^{2}}{\mathrm{n} 1}+\frac{\mathrm{T}^{2}}{\mathrm{n} 2}+\ldots+\frac{\mathrm{Tk}^{2}}{\mathrm{nk}}\right)-3(\mathrm{~N}+1)$

Formula (1)

$$
\begin{aligned}
& \mathrm{R}_{\text {FMEA-D }}=\frac{12}{15(15+1)}\left(\frac{56^{2}}{5}+\frac{49^{2}}{5}+\ldots+\frac{15^{2}}{5}\right)-3(15+1) \\
& \mathrm{R}_{\text {FMEA-D }}=9.62
\end{aligned}
$$

If $\mathrm{R}_{\mathrm{FMEA}-\mathrm{D}}$ value is lower than corresponding value of Chi-Square distribution table. Consequently, that means that the medians of detection for all years are equal [18], otherwise they are different and therefore the level of improvements in detection of failures precisely determined by lowest scores of ranking throughout the compared years in Table 5. Using Chi-Square distribution, the degree of freedom (df) determined by the formula:

$\mathrm{K}-1$. Number of years $(\mathrm{K})=3$; then $\mathrm{df}=3-1=2$,

\begin{tabular}{|c|c|c|c|}
\hline Occurrence (0) & $\mathbf{2 0 1 5}$ & $\mathbf{2 0 1 6}$ & $\mathbf{2 0 1 7}$ \\
\hline Evaluation 1 & $7(13)$ & $4(6.5)$ & $5(9.5)$ \\
\hline Evaluation 2 & $6(11)$ & $5(9.5)$ & $3(3.5)$ \\
\hline Evaluation 3 & $7(13)$ & $8(15)$ & $4(6.5)$ \\
\hline Evaluation 4 & $4(6.5)$ & $7(13)$ & $2(2)$ \\
\hline Evaluation 5 & $3(3.5)$ & $4(6.5)$ & $1(1)$ \\
\hline Sum of ranks & 47 & 50.5 & 22.5 \\
\hline Mean of the ranks & 9.4 & 10.1 & 4.5 \\
\hline $\begin{array}{c}\text { Mean of evaluations (used for } \\
\text { conventional FMEA) }\end{array}$ & 5.4 & 5.6 & 3 \\
\hline
\end{tabular}

Table 3: Ranked occurrence observations table.

\begin{tabular}{|c|c|c|c|}
\hline Severity (S) & $\mathbf{2 0 1 5}$ & $\mathbf{2 0 1 6}$ & $\mathbf{2 0 1 7}$ \\
\hline Evaluation1 & $4(8.5)$ & $5(12)$ & $4(8.5)$ \\
\hline Evaluation2 & $4(8.5)$ & $3(4)$ & $6(14.5)$ \\
\hline Evaluation3 & $3(4)$ & $5(12)$ & $5(12)$ \\
\hline Evaluation4 & $2(1)$ & $4(8.5)$ & $6(14.5)$ \\
\hline Evaluation5 & $3(4)$ & $3(4)$ & $3(4)$ \\
\hline Sum of ranks & 26 & 40.5 & 53.5 \\
\hline Mean of the ranks & 5.2 & 8.1 & 10.7 \\
\hline $\begin{array}{c}\text { Mean of evaluations (used for } \\
\text { conventional FMEA) }\end{array}$ & 3.2 & 4 & 4.8 \\
\hline
\end{tabular}

Table 4: Ranked severity observations table.
Therefore, back to chi-square distribution table in the corresponding degree of freedom with 0.05 significance level of 0.05 is 5.991

$\mathrm{R}_{\text {FMEA-D }}$ value (9.62) is larger than corresponding value (5.991), which means that the detection medians are not equal throughout the three years. Based on the lowest mean of the ranks the improvement detected. This method applied to investigate both occurrence and severity separately to improve reliability of instrument. Using R-FMEA increases the likeliness of addressing every single element in traditional FMEA; and that consequently improves tracking causes of errors back

\begin{tabular}{|c|c|c|c|c|c|c|c|c|c|}
\hline Comparison & \multicolumn{3}{|c|}{2015} & \multicolumn{3}{|c|}{2016} & \multicolumn{3}{|c|}{2017} \\
\hline $\begin{array}{l}\text { Conventional FMEA } \\
\text { using merely RPN ( S } \\
{ }^{*} \mathrm{O}^{*} \mathrm{D} \text { ) }\end{array}$ & \multicolumn{3}{|c|}{$\begin{array}{l}\left(7.4^{*} 5.4^{*} 3.2\right)= \\
127.87 \approx 1.27\end{array}$} & \multicolumn{3}{|c|}{$\begin{array}{l}\left(6.4^{*} 5.6 * 4\right)= \\
143.36 \approx 1.43\end{array}$} & \multicolumn{3}{|c|}{$\begin{array}{l}\left(2.2^{*} 3^{*} 4.8\right)= \\
31.68 \approx 0.31\end{array}$} \\
\hline \multirow{6}{*}{$\begin{array}{l}\text { R-FMEA using } \\
\text { Kruskal-Wallis test } \\
\text { using formula 1,2, and } \\
3\end{array}$} & \multicolumn{9}{|c|}{$\begin{array}{l}\text { Chi -square distribution corresponding value at level of } \\
\text { significance of } 0.05 \text { and df of } 2=5.991\end{array}$} \\
\hline & \multicolumn{8}{|c|}{$\begin{array}{l}\text { RFMEA-D }=9.62 \geq 5.991 \rightarrow \text { detection medians } \\
\text { are not equal statistically. The lowest mean of } \\
\text { ranks is the improvement. }\end{array}$} & \\
\hline & \multicolumn{8}{|c|}{$\begin{array}{l}\text { RFMEA-O }=4.655<5.991 \rightarrow \text { occurrence medians } \\
\text { are equal statistically. No need to inspect mean of } \\
\text { ranks. }\end{array}$} & \\
\hline & \multicolumn{8}{|c|}{$\begin{array}{l}\text { RFMEA-S }=3.785<5.991 \rightarrow \text { severity medians are } \\
\text { equal statistically. No need to inspect mean of } \\
\text { ranks. }\end{array}$} & \\
\hline & \multicolumn{2}{|c|}{2015} & \multicolumn{3}{|c|}{2016} & \multicolumn{3}{|c|}{2017} & \multirow[b]{2}{*}{$S$} \\
\hline & D & $\mathrm{O}$ & $S$ & $\mathrm{D}$ & $\mathrm{O}$ & $S$ & $D$ & $\mathrm{O}$ & \\
\hline Mean of the ranks & 11.2 & 9.4 & 5.2 & 9.8 & $\begin{array}{l}10 . \\
1\end{array}$ & 8.1 & 3 & 4.5 & $\begin{array}{l}10 . \\
7\end{array}$ \\
\hline
\end{tabular}
as if it comes from $\mathrm{S}, \mathrm{O}$, or D.

Table 5: Comparison between conventional FMEA and R-FMEA table.

In FMEA, the RPN indicates collectively that the general failure prediction is deteriorates in 2016, while in 2017 profoundly improved. This fluctuation might represent the bias in reliability of using merely RPN. In contrast, in R-FMEA each single cause of error investigated separately using statistics to enhance the reliability. Using KruskalWallis test in R-FMEA reveals that there is no change in occurrence and severity except detection in all three years. The detection was improved in last two consecutive years which is not compatible with FMEA results.

\section{References}

1. Fassett WE (2011) Key performance outcomes of patient safety curricula: root cause analysis, failure mode and effects analysis, and structured communications skills. Am J Pharm Educ 75: 164.

2. Stamatis DH (2003) Failure Mode and Effect Analysis: FMEA from Theory to Execution. ASQ Quality Press.

3. Guerrero HH, Bradley JR (2013) Failure Modes and Effects Analysis: An Evaluation of Group versus Individual Performance. Production and Operations Management 22: 1524-1539.

4. Sears K, Stockley D, Broderick B (2015) Influencing the Quality Risk and Safety Movement in Healthcare in Conversation with International Leaders. Ashgate Publishing Limited, UK.

5. Jacobs LA (2000) An analysis of the concept of risk. Cancer Nurs 23: 12-19. 
Citation: Alsubiaee KM, Alotaibi AF, Alshehri AS, Alassaf MA (2017) Reverse Evaluation of Failure Mode and Effects Analysis Model: A New

6. Shattell M (2004) Risk: A concept analysis. Nurs Forum 39: 11-17.

7. Kingston M, Evans S, Smith B, Berry J (2004) Attitudes of doctors and nurses towards incident reporting: a qualitative analysis. Med J Aust 181: 36-39.

8. Zegers M, De Bruijne M, Wagner C, Hoonhout LH, Waaijman R, et al. (2009) Adverse events and potentially preventable deaths in Dutch hospitals: results of a retrospective patient record review study. Qual Saf Health Care 18: 297-302.

9. Baker GR, Norton PG, Flintoft V, Blais R, Brown A, et al. (2004) The Canadian Adverse Events Study: the incidence of adverse events among hospital patients in Canada. CMAJ 170: 1678-1686.

10. Thornton E, Brook OR, Mendiratta-Lala M, Hallett DT, Kruskal JB (2011) Application of Failure Mode and Effect Analysis in a Radiology Department. Radiographics 31: 281-293.

11. Kahraman C, Yanı S (2015) Intelligent Decision Making in Quality Management: Theory and Applications. Springer International Publishing, USA.

12. Van Den Bos J, Rustagi K, Gray T, Halford M, Ziemkiewicz E, et al. (2011) The $\$ 17.1$ billion problem: the annual cost of measurable medical errors. Health Aff (Millwood) 30: 596-603.
13. Potts HW, Anderson JE, Colligan L, Leach P, Davis S, et al. (2014) Assessing the validity of prospective hazard analysis methods: a comparison of two techniques. BMC Health Serv Res 14: 41.

14. Oldenhof MT, van Leeuwen JF, Nauta MJ, de Kaste D, OdekerkenRombouts YM, et al. (2011) Consistency of FMEA used in the validation of analytical procedures. J Pharm Biomed Anal 54: 592-595.

15. Yang F, Cao N, Young L, Howard J, Logan W, et al. (2015) Validating FMEA output against incident learning data: A study in stereotactic body radiation therapy. Med phys 42: 2777-2785.

16. Donabedian A (1988) The quality of care: How can it be assessed? JAMA 260: 1743-1748.

17. Shebl NA, Franklin BD, Barber N (2012) Failure mode and effects analysis outputs: are they valid? BMC Health Serv Res 12: 150-150.

18. Triola MM, Triola MF (2006) Biostatistics for the biological and health sciences. Pearson Addison-Wesley, Boston. 